\title{
Evaluation of the Prevalence of Vitamin D Deficiency in Postmenopausal Women with Fractures in Different Hospitals in Tangail
}

\author{
Dr. Aklima Akter ${ }^{*}$, Dr. Mokhlesur Rahman ${ }^{2}$, Dr. Fowzia Yasmin ${ }^{3}$, Dr. Nazma Khalil ${ }^{4}$, Dr. S.M. Rokonuzzaman ${ }^{5}$, Dr.
} Sudhangsu Kumar ${ }^{6}$

${ }^{1}$ Assistant Professor, Department of Gynae \& Obs, Sheikh Hasina Medical College, Tangail, Bangladesh

${ }^{2}$ Assistant Professor, Ortho Surgery Department, Sheikh Hasina Medical College, Tangail, Bangladesh

${ }^{3}$ Assistant Professor, Department of Gynae \& Obs, SSMC \& Mitford Hospital, Dhaka, Bangladesh

${ }^{4}$ Junior Consultant, Department of Gynae \& Obs, Sheikh Hasina Medical College, Tangail, Bangladesh

${ }^{5,6}$ Assistant Professor, Ortho Surgery Department, Sheikh Hasina Medical College, Tangail, Bangladesh

DOI: $10.36347 /$ sjams.2020.v08i12.021

| Received: 30.11 .2020 | Accepted: 12.12.2020 | Published: 19.12.2020

*Corresponding author: Dr. Aklima Akter

Abstract

Original Research Article

Background: Vitamin D deficiency is common among the post-menopausal women and the prevalence of vitamin D deficiency is high in postmenopausal women with fractures regardless of whether the injury mechanism was high or low energy. Objective: To evaluate the prevalence of vitamin D deficiency in postmenopausal women with fractures that revealed a high prevalence of vitamin D deficiency regardless of whether the injury mechanism was high or low energy. Methodology: The study was a cross sectional observational study conducted in different hospitals in Tangail over a period of 2 years from 1 st January 2017 to $31^{\text {st }}$ December 2018 . Total 150 postmenopausal women aged 50 years or older with long bone or pelvic fractures and measurements of serum vitamin D levels were included and those with pathological fractures, metabolic diseases such as Paget's disease and hyperparathyroidism and isolated hand or foot fractures were excluded. Result: Majority 72 (61.0\%) patients were found osteoporosis in low energy group and $12(37.5 \%)$ in high-energy group. Median BMD at the total femur was found -2.1 in low energy group and -1.3 in high-energy group, which were statistically significant $(\mathrm{p}<0.05)$ between two groups. Calcium and vitamin $\mathrm{D}$ supplements after injury were statistically significant $(\mathrm{p}<0.05)$ within the low and high-energy group in comparison prior to the injury. Conclusion: Majority patients were found osteoporosis in low energy group in comparison to highenergy group. Calcium and vitamin D supplements after injury were statistically significant within the low and highenergy group compared with before injury.

Keywords: Fracture, Vitamin D deficiency, Osteoporosis, supplementation.

Copyright $\left({ }^{\circ} 2020\right.$ The Author(s): This is an open-access article distributed under the terms of the Creative Commons Attribution 4.0 International License (CC BY-NC 4.0) which permits unrestricted use, distribution, and reproduction in any medium for non-commercial use provided the original author and source are credited.

\section{INTRODUCTION}

Vitamin D deficiency is common among postmenopausal women and it is important to treat vitamin $\mathrm{D}$ deficiency to prevent falls and fractures in patients with osteoporosis [1]. Vitamin D is a steroid hormone that affects human health. Vitamin D can be acquired from the diet, e.g., in fish oil or fortified dairy products, but approximately $90 \%$ of the body's vitamin D is synthesized via skin after exposure to solar ultraviolet B (UVB) radiation [2]. Vitamin D deficiency is a risk factor for fall and fracture among post-menopausal women with osteoporosis and vitamin D deficiency is a pandemic health problem which was attributed for several health problems and well documented in different parts of the globe including Bangladesh [3,4]. Moderate level of sun exposure is the major source for Vitamin D as only limited dietary sources are rich in Vitamin D [5]. Vitamin D deficiency is known to result in osteopenia and osteomalacia, and to worsen osteoporosis [6]. It will also lead to muscle weakness, resulting in an increased fall risk, and corresponding risk of fractures [7]. Furthermore, the vitamin D status of adult patients with a long bone fracture affects the healing of fractures [8]. The fracture-healing process can be divided into four overlapping stages: inflammation, soft callus formation, hard callus formation, and bone remodeling [9]. Vitamin D is important in bone health, but recent research also points out its essential role in extra skeletal functions, including skeletal muscle growth, immune and cardiopulmonary functions and inflammatory modulation, which influence athletic performance. Vitamin D can also interact with extra skeletal tissues to modulate injury recovery and also influence the risk of infection [10]. The prevalence of vitamin D deficiency in postmenopausal women with fractures and revealed a high prevalence of vitamin $\mathrm{D}$ deficiency regardless of 
whether the injury mechanism was high or low energy. However, the prescription rate of vitamin D supplementation was lower in the high-energy compared to the low-energy injury group [11].

\section{Materials ANd Methods}

The study was a cross sectional observational study conducted in different hospitals in Tangail over a period of 2 years from 1st January 2017 to $31^{\text {st }}$ December 2018. Postmenopausal women aged 50 years or older with long bone or pelvic fractures and measurements of serum vitamin D levels were included, and those with pathologic fractures, metabolic diseases such as Paget's and hyperparathyroidism, and isolated hand or foot fractures were excluded. Postmenopausal status was obtained from medical records. The patients were divided into two groups according to the mechanism of injury: low-energy (118 patients) or high energy injury (32 patients). Low-energy injury was defined as falls from heights of $1 \mathrm{~m}$ or less. Measurement of 25-OH-Vitamin D3 was performed using radioimmunoassay (Bio Source Europe S.A., Nivelles, Belgium). Deficiency was defined as 0-20 $\mathrm{ng} / \mathrm{mL}$, insufficiency as $20-30 \mathrm{ng} / \mathrm{mL}$, sufficiency as $30-150 \mathrm{ng} / \mathrm{mL}$, and toxicity as $150 \mathrm{ng} / \mathrm{mL}$ or more. Bone turnover markers including serum osteocalcin, parathyroid hormone (PTH), C-telopeptide (CTX), Ca, $\mathrm{P}$, alkaline phosphatase (ALP), and albumin were studied. Body mass index (BMI), history of prior osteoporosis medications, and prescription of osteoporosis medication after fracture was assessed. Bone mineral density (BMD) was measured with dualenergy x-ray absorptiometry (DEXA, Prodigy Advance, GE Healthcare Lunar, Madison, WI, USA) and BMD of the femoral neck, total hip area, and first to fourth lumbar vertebrae were recorded. Prevalence of vitamin deficiency was determined, and the rate was compared between the two groups, along with the postoperative prescription rate of vitamin D supplementation. Data were processed and analyzed using SPSS ver23(Statistical Package for Social Sciences). The test statistics used to analyze the data were descriptive statistics. The summarized data were presented in the form of tables.

\section{RESULT}

Majority 37(31.4\%) patients were found femur injury in low energy group and $2(6.3 \%)$ in high energy group (Table-1). Mean age, BMI, C Terminal Telopeptide, osteocalcin, iPTH, calcium, phosphorus, alkaline phosphatase and albumin were not statistically significant $(p>0.05)$ between two groups (Table-2). The mean vitamin $\mathrm{D}$ was found $23.2 \pm 9.3 \mathrm{ng} / \mathrm{ml}$ in low energy group and $21.7 \pm 9.4 \mathrm{ng} / \mathrm{ml}$ in high energy group. The difference was not statistically significant $(\mathrm{p}>0.05)$ between two groups (Table-3). Majority 72(61.0\%) patients were found osteoporosis in low energy group and $12(37.5 \%)$ in high-energy group. Median BMD at the total femur was found -2.1 in low energy group and -1.3 in high-energy group which were statistically significant $(\mathrm{p}<0.05)$ between two groups $($ Table-4). In before injury, 19(16.1\%) patients received treatment with calcium and vitamin D supplements in the low energy group and $1(3.1 \%)$ in high energy group. In after injury, 69(58.5\%) patients were treatment received calcium and vitamin D supplements in the low energy group and $10(31.3 \%)$ in high energy group. The difference were statistically significant $(\mathrm{p}<0.05)$ between two groups. Calcium and vitamin D supplements- after injury were statistically significant $(p<0.05)$ within the low and high energy compare with before injury (Table-5). In before injury, 22(18.6\%) patients were treatment received osteoporosis supplementation in the low energy group and $1(3.1 \%)$ in high energy group. In after injury, 72(61.0\%) patients were treatment received osteoporosis supplementation in the low energy group and $12(37.5 \%$ ) in high energy group. The difference were statistically significant $(p<0.05)$ between two groups. Osteoporosis supplement- after injury were statistically significant $(\mathrm{p}<0.05)$ within the low and high energy compare with before injury (Table-6).

Table-1: Fracture site of the study patients

\begin{tabular}{|l|l|l|l|l|}
\hline \multirow{2}{*}{} & \multicolumn{2}{|l|}{ Low energy $(\mathbf{n = 1 1 8})$} & \multicolumn{2}{l|}{ High energy $(\mathbf{n = 3 2})$} \\
\cline { 2 - 5 } & $\mathbf{n}$ & $\mathbf{\%}$ & $\mathbf{n}$ & $\mathbf{\%}$ \\
\hline Humerus & 7 & 5.9 & 0 & 0.0 \\
\hline Radius & 27 & 22.9 & 2 & 6.3 \\
\hline Pelvic ring injury & 3 & 2.5 & 6 & 18.8 \\
\hline Femur & 37 & 31.4 & 2 & 6.3 \\
\hline Patella & 10 & 8.5 & 1 & 3.1 \\
\hline Tibia & 4 & 3.4 & 8 & 25.0 \\
\hline Multiple & 30 & 25.4 & 13 & 40.6 \\
\hline
\end{tabular}


Table-2: Association between demographic characteristic and laboratory findings with injury mechanism

\begin{tabular}{|l|l|l|l|}
\hline \multirow{2}{*}{ Variable } & Low energy $(\mathbf{n = 1 1 8})$ & High energy $(\mathbf{n}=32)$ & \multirow{2}{*}{ P value } \\
\cline { 2 - 3 } & Mean \pm SD & Mean \pm SD & \\
\hline Age $($ years) & $69.7 . \pm 10.2$ & $66.4 \pm 9.3$ & 0.101 \\
\hline BMI $\left(\mathrm{kg} / \mathrm{m}^{2}\right)$ & $23.5 \pm 3.8$ & $23.1 \pm 3.0$ & 0.583 \\
\hline C Terminal Telopeptide $(\mathrm{ng} / \mathrm{mL})$ & $0.52 \pm 0.23$ & $0.61 \pm 0.29$ & 0.066 \\
\hline Osteocalcin (ng/ml) & $14.8 \pm 6.9$ & $15.9 \pm 8.6$ & 0.450 \\
\hline iPTH (pg/ml) & $49.4 \pm 24.5$ & $44.7 \pm 21.3$ & 0.324 \\
\hline Calcium (mg/dl) & $7.9 \pm 0.7$ & $8.0 \pm 0.8$ & 0.488 \\
\hline Phosphorus (mg/dl) & $3.3 \pm 0.7$ & $3.2 \pm 0.9$ & 0.503 \\
\hline Alkaline phosphatase (U/L) & $118.2 \pm 78.5$ & $145.1 \pm 89.2$ & 0.097 \\
\hline Albumin (g/dL) & $3.1 \pm 0.5$ & $3.2 \pm 0.4$ & 0.298 \\
\hline
\end{tabular}

$\mathrm{P}$ value reached from unpaired t-test

Table-3: Association between vitamin $D$ with injury mechanism

\begin{tabular}{|c|c|c|c|c|c|}
\hline \multirow[t]{2}{*}{ Vitamin D (ng/ml) } & \multicolumn{2}{|c|}{ Low energy $(n=118)$} & \multicolumn{2}{|c|}{ High energy $(n=32)$} & \multirow[t]{2}{*}{ P value } \\
\hline & $\mathbf{n}$ & $\%$ & $\mathbf{n}$ & $\%$ & \\
\hline Normal $(\geq 30)$ & 28 & 23.7 & 3 & 9.4 & \\
\hline Insufficiency (20.0-29.9) & 21 & 17.8 & 6 & 18.8 & \\
\hline Deficiency $(<20.0)$ & 69 & 58.5 & 23 & 71.9 & \\
\hline Mean \pm SD & \multicolumn{2}{|c|}{$23.2 \pm 9.3$} & \multicolumn{2}{|c|}{$21.7 \pm 9.4$} & 0.421 \\
\hline
\end{tabular}

Table-4: Association between bone mineral density with injury mechanism

\begin{tabular}{|l|l|l|l|l|l|}
\hline & \multicolumn{2}{|l|}{ Low energy $(\mathbf{n = 1 1 8})$} & \multicolumn{2}{l|}{ High energy $(\mathbf{n = 3 2})$} & \multirow{2}{*}{ P value } \\
\cline { 2 - 5 } & $\mathbf{n}$ & $\mathbf{\%}$ & $\mathbf{n}$ & $\mathbf{\%}$ & \\
\hline Bone mineral density & & & & & \\
\hline Normal $(\geq-1.0)$ & 3 & 2.5 & 9 & 28.1 & \\
\hline Oteopenia (-1.1 to -2.49) & 43 & 36.4 & 11 & 34.4 & $\mathbf{0 . 0 0 1}$ \\
\hline Oteoporosis ( $\leq-2.5)$ & 72 & 61.0 & 12 & 37.5 & \\
\hline Median BMD at the lumbar spine & -2.2 & -2.0 & & 0.462 \\
\hline Median BMD at the femur neck & -2.2 & -1.9 & 0.143 \\
\hline Median BMD at the total femur & -2.1 & -1.3 & $\mathbf{0 . 0 0 1}$ \\
\hline
\end{tabular}

$\mathrm{P}$ value reached from chi square test \& unpaired t-test

Table-5: Association between low calcium+ vitamin D medication with injury mechanism

\begin{tabular}{|l|l|l|l|l|l|}
\hline \multirow{2}{*}{ Calcium+ vitamin D medication } & \multicolumn{2}{l|}{ Low energy $(\mathbf{n = 1 1 8})$} & \multicolumn{2}{l|}{ High energy $(\mathbf{n = 3 2})$} & \multirow{2}{*}{ P value } \\
\cline { 2 - 5 } & $\mathbf{n}$ & $\mathbf{\%}$ & $\mathbf{n}$ & $\mathbf{\%}$ & \\
\hline Before injury & 19 & 16.1 & 1 & 3.1 & $\mathbf{0 . 0 4 1}$ \\
\hline After injury & 69 & 58.5 & 10 & 31.3 & $\mathbf{0 . 0 0 6}$ \\
\hline P value (before vs after injury) & $\mathbf{0 . 0 0 1}$ & $\mathbf{0 . 0 0 3}$ & \\
\hline
\end{tabular}

$\mathrm{P}$ value reached from unpaired \& paired t-test

Table-6: Association between osteoporosis medication with injury mechanism

\begin{tabular}{|l|l|l|l|l|l|}
\hline \multirow{2}{*}{ Osteoporosis medication } & \multicolumn{2}{|l|}{ Low energy (n=118) } & \multicolumn{2}{l|}{ High energy (n=32) } & \multirow{2}{*}{ P value } \\
\cline { 2 - 5 } & $\mathbf{n}$ & $\mathbf{\%}$ & $\mathbf{n}$ & $\mathbf{\%}$ & \\
\hline Before injury & 22 & 18.6 & 1 & 3.1 & $\mathbf{0 . 0 2 1}$ \\
\hline After injury & 72 & 61.0 & 12 & 37.5 & $\mathbf{0 . 0 1 7}$ \\
\hline P value (before vs after injury) & $\mathbf{0 . 0 0 1}$ & $\mathbf{0 . 0 0 1}$ & \\
\hline
\end{tabular}

$\mathrm{P}$ value reached from unpaired $\&$ paired t-test

\section{DiscUSSION}

Calcium and vitamin D deficiency may contribute to fracture healing complications observed in patients with osteoporosis [12,13] because calcium is essential for fracture-callus mineralization [14]. Furthermore, it has been reported that among elderly patients with hip fractures, $80 \%$ had secondary causes for bone loss, mainly related to disturbed $\mathrm{Ca}$ and vitamin D homeostasis [15].

In current study observed that the majority $37(31.4 \%)$ patients were found femur injury in low 
energy group and 2(6.3\%) in high energy group. Similar study reported by Lee and Kim [11].

In this study showed the mean age, BMI, C Terminal Telopeptide, osteocalcin, iPTH, calcium, phosphorus, alkaline phosphatase and albumin were not statistically significant $(p>0.05)$ between two groups. Lee and Kim reported there was no difference in age between the low and high-energy groups [11]. BMI, serum calcium, phosphorus, PTH, osteocalcin, CTX, ALP and albumin were also similar between the two groups. Al-Yatama et al., reported bone turnover and mineralization are affected by vitamin D status such that vitamin D deficiency may lead to low BMD [16]. Reduced BMD, which is also known as osteopenia, may lead to osteoporosis and an increased risk of fracture if left untreated [17, 18]. Vitamin D deficiency is prevalent among patients with osteoporosis [19]. Supplementation with vitamin D and calcium has been shown to reduce the risk of hip fractures among elderly women [20]. Hannemann et al., also observed median (1st-3rd quartile) serum OC concentrations were 14.4 $\mathrm{ng} / \mathrm{mL}(11.3-18.5 \mathrm{ng} / \mathrm{mL})$ in premenopausal women and $18.6 \mathrm{ng} / \mathrm{mL}(13.6-25.6 \mathrm{ng} / \mathrm{mL})$ in postmenopausal women [21].

In this study observed that the mean vitamin $\mathrm{D}$ was found $23.2 \pm 9.3 \mathrm{ng} / \mathrm{ml}$ in low energy group and $21.7 \pm 9.4 \mathrm{ng} / \mathrm{ml}$ in high energy group. The difference was not statistically significant $(p>0.05)$ between two groups. Lee and Kim reported that the prevalence of vitamin D deficiency was $60.7 \%$ and $65.5 \%$ in the low and high-energy groups $(\mathrm{p}=0.673)$, respectively [11]. This finding is consistent with the results of the 6th Korea National Health and Nutrition Examination Survey (KNHANES), which showed a prevalence of vitamin D deficiency of $74.2 \%$ in the general population [22]. In Bangladesh serum 25(OH)D <37.7 nmol/1 was seen in $50 \%$ of those in low income groups (median $36.7 \mathrm{nmol} / \mathrm{l}$ ) compared to $38 \%$ of high income groups (median $(43.5 \mathrm{nmol} / \mathrm{L})$. Prevalence of low 25(OH)D increased in lactating women [23]. Vitamin D insufficiency $(<40 \mathrm{nmol} / \mathrm{l})$ was common $(80 \%)$ regardless of age, lifestyle and clothing in study from Dhaka [24].

In this study showed that the majority $72(61.0 \%)$ patients were found osteoporosis in low energy group and $12(37.5 \%)$ in high energy group. Median BMD at the total femur was found -2.1 in low energy group and -1.3 in high energy group. Which were statistically significant $(\mathrm{p}<0.05)$ between two groups. Lee and Kim study observed BMD was evaluated in $85.0 \%$ (91) of patients in the low energy group and $82.8 \%$ (24) in the high-energy group ( $p$ $=0.441$ ) [11]. The prevalence of osteoporosis ( $\mathrm{T}$-score $\leq-2.5)$ was found to be higher in the low-energy group $(62.6 \%$ vs. $37.5 \%, \mathrm{p}=0.024)$. BMD in the spine and femoral neck, however, were found to be similar between the two groups $(\mathrm{p}=0.368, \mathrm{p}=0.067$, respectively), but BMD in the total femur was lower in the low-energy group $(\mathrm{p}=0.005)$. This practice is consistent with the National Osteoporosis Foundation (NOF) guidelines based on FRAX results for the US population, which suggest that treatment should be provided to patients with a $20 \%$ or greater 10 -year risk of osteoporotic fracture or a $3 \%$ or greater 10-year risk of hip fracture [25]. Al-Yatama et al., regarding the direct relationship between vitamin D and BMD [2, 18, $19,24,27]$. In addition, high levels of bone turnover markers in the blood may indicate increased bone loss [28]. A cross-sectional study revealed that patients with fractures had higher bone turnover marker levels than individuals without fractures [29]. It has been reported that women lose approximately $1 \%$ of their spinal bone density across the menstrual cycle and after menopause [30]. A cross-sectional investigation that included 635 healthy women of European descent demonstrated that those with the lowest bone mass had the highest levels of osteocalcin, NTX, CTX, and BALP [31].

In this study showed in before injury, $19(16.1 \%)$ patients were treatment received calcium and vitamin D supplements in the low energy group and $1(3.1 \%)$ in high energy group. In after injury, $69(58.5 \%)$ patients were treatment received calcium and vitamin D supplements in the low energy group and $10(31.3 \%)$ in high energy group. The difference were statistically significant $(\mathrm{p}<0.05)$ between two groups. Calcium and vitamin D supplements- after injury were statistically significant $(\mathrm{p}<0.05)$ within the low and high energy compare with before injury. Lee and Kim fifteen patients $(14.0 \%)$ in the low-energy group were on $\mathrm{Ca}$ and vitamin D supplements prior to injury, compared to only one patient $(3.4 \%)$ in the high-energy group $(\mathrm{p}=$ $0.100)$ [11]. The rate of postoperative $\mathrm{Ca}$ and vitamin $\mathrm{D}$ supplementation was higher in the low-energy group (85.0\%, 91 patients) than the high-energy group (58.6\%, 17 patients) $(\mathrm{p}=0.003)$. In both groups, the prescription rates of calcium and vitamin $D$ supplementation increased after the occurrence of fracture $(\mathrm{p}<0.001, \mathrm{p}<0.001)$.

In current study showed in before injury, $22(18.6 \%)$ patients were treatment received osteoporosis supplementation in the low energy group and $1(3.1 \%)$ in high energy group. In after injury, $72(61.0 \%)$ patients were treatment received osteoporosis supplementation in the low energy group and $12(37.5 \%)$ in high energy group. The difference were statistically significant $(p<0.05)$ between two groups. Osteoporosis supplement- after injury were statistically significant $(\mathrm{p}<0.05)$ within the low and high energy compare with before injury. Lee and Kim reported that the rate of osteoporosis treatment prior to injury was $18 \%$ in the low-energy group vs. $7 \%$ in the high-energy group $(\mathrm{p}=0.123)$ [11]. Osteoporosis medication was generally prescribed more frequently in the low-energy group than in the high energy group $(73.8 \%$ vs. $48 \%, \mathrm{p}=0.009)$. In both groups, the 
prescription rates of osteoporosis medication increased after the occurrence of fracture $(\mathrm{p}<0.001, \mathrm{p}<0.001)$.

\section{Conclusion}

Majority patients were found osteoporosis in low energy group in comparison to high energy group. Calcium and vitamin D supplements- after injury were statistically significant within the low and high energy compare with before injury.

\section{REFERENCE}

1. Suganthan N, Kumanan T, Kesavan V, Aravinthan M, Rajeshkannan N. Vitamin D status among postmenopausal osteoporotic women: a hospital based cross-sectional study from Northern Sri Lanka. BMC nutrition. 2020;6(1):1-8.

2. Al-Yatama FI, AlOtaibi F, Al-Bader MD, AlShoumer KA. The Effect of Clothing on Vitamin D Status, Bone Turnover Markers, and Bone Mineral Density in Young Kuwaiti Females. Hindawi International Journal of Endocrinology, 2019;10:1-10.

3. Inderjeeth CS, Harrod W, Andrisha JI. Osteoporosis in older people, managing the risks. Med Today. 2019;20(8):10-8.

4. Holick MF, Chen TC. Vitamin D deficiency: a worldwide problem with health consequences. Am J Clin Nutr. 2008;87(suppl):1080S-6S.

5. Holick MF, Matsuoka LY, Wortsman J. Age, vitamin D, and solar ultraviolet. Lancet (London, England). 1989;2(8671):1104-5.

6. Holick MF. Vitamin D deficiency. N Engl J Med. 2007;357:266-281.

7. Marcelli C, Chavoix C, Dargent-Molina P. Beneficial effects of vitamin $\mathrm{D}$ on falls and fractures: is cognition rather than bone or muscle behind these benefits?. Osteoporos Int. 2015;26:110 .

8. Brinker MR, O'Connor DP, Monla YT, Earthman TP. Metabolic and endocrine abnormalities in patients with nonunions. J Orthop Trauma. 2007;21:557-570.

9. Schindeler A, McDonald MM, Bokko P, Little DG. Bone remodeling during fracture repair: the cellular picture. Semin Cell Dev Biol. 2008;19:459-466.

10. de la Puente Yagüe M, Collado Yurrita L, Cuadrado Cenzual MA. Role of vitamin $d$ in athletes and their performance: Current concepts and new trends. Nutrients. 2020;12(2):579.

11. Lee JS, Kim JW. Prevalence of vitamin D deficiency in postmenopausal high-and low-energy fracture patient. Archives of osteoporosis. 2018;13(1):109.

12. Nikolaou VS, Efstathopoulos N, Kontakis G, Kanakaris NK, Giannoudis PV. The influence of osteoporosis in femoral fracture healing time. Injury. 2009;40:663-668.

13. Giannoudis P, Tzioupis C, Almalki T, Buckley R. Fracture healing in osteoporotic fractures: is it really different? A basic science perspective. Injury 2007;38(Suppl 1):S90-S99.

14. Lemaire RG. Calcium metabolism in fracture healing: An experimental kinetic study in rats, using Ca45. J Bone Joint Surg Am 1966;48:11561170 .

15. Solomon DH, Finkelstein JS, Katz JN, Mogun H, Avorn J. Underuse of osteoporosis medications in elderly patients with fractures. Am J Med 2003;115:398-400.

16. Man PW, van der Meer IM, Lips P, Middelkoop BJ. Vitamin D status and bone mineral density in the Chinese population: a review. Archives of Osteoporosis. 2016;11(1):14.

17. Soomro RR, Ahmed SI, Khan M. Frequency of osteopenia and associated risk factors among young female students. Journal of Pakistan Medical Association. 2017;67:365-8.

18. Li S, Ou Y, Zhang H, Zhang Z, Zhou H, Liu L, Sheng Z, Liao E. Vitamin D status and its relationship with body composition, bone mineral density and fracture risk in urban central south Chinese postmenopausal women. Annals of Nutrition and Metabolism. 2014;64(1):13-9.

19. Kamineni V, Latha AP, Ramathulasi K. Association between serum 25-hydroxyvitamin D levels and bone mineral density in normal postmenopausal women. Journal of mid-life health. 2016;7(4):163.

20. Chapuy MC, Arlot ME, Duboeuf F. Vitamin D3 and calcium to prevent hip fractures in elderly women. The New England Journal of Medicine, 1992; 327(23): 1637-1642.

21. Hannemann A, Friedrich N, Spielhagen C, Rettig $\mathrm{R}$, Ittermann $\mathrm{T}$, Nauck $\mathrm{M}$, Wallaschofski $\mathrm{H}$. Reference intervals for serum osteocalcin concentrations in adult men and women from the study of health in Pomerania. BMC endocrine disorders. 2013 Dec 1;13(1):11.

22. Kim A, Yun JM. Association of diabetes with serum vitamin D in Korean adults: analysis of the Korea National Health and Nutrition Examination Survey (2013-2014). J Korean Diet Assoc. 2017;23:39-53.

23. Islam MZ, Lamberg-Allardt C, Karkkainen M, Outila T, Salamatullah Q, Shamim AA. Vitamin D deficiency: a concern in premenopausal Bangladeshi women of two socio-economic groups in rural and urban region. Eur J Clin Nutr. 2002;56:51-56.

24. Islam MZ, Akhtaruzzaman M, Lamberg-Allardt C. Hypovitaminosis D is common in both veiled and nonveiled Bangladeshi women. Asia Pac J Clin Nutr. 2006;15:81-87.

25. Mechanick J, Camacho P, Cobin R, Garber A, Garber J, Gharib H, Petak S, Rodbard H, Trence D. American Association of Clinical Endocrinologists protocol for standardized production of clinical practice guidelines-2010 
update. Endocrine Practice. 2010 Mar 1;16(2):27083.

26. Kruavit A, Chailurkit LO, Thakkinstian A, Sriphrapradang C, Rajatanavin R. Prevalence of vitamin $\mathrm{D}$ insufficiency and low bone mineral density in elderly Thai nursing home residents. BMC geriatrics. 2012;12(1):49.

27. Kharroubi A, Saba E, Smoom R, Bader K, Darwish H. Serum 25-hydroxyvitamin D and bone turnover markers in Palestinian postmenopausal osteoporosis and normal women. Archives of Osteoporosis. 2017;12(1):13.

28. Singer FR, Eyre DR. Using biochemical markers of bone turnover in clinical practice. Cleveland Clinic journal of medicine. 2008;75(10):739-50.
29. Cheung CK, Panesar NS, Lau E, Woo J, Swaminathan R. Increased bone resorption and decreased bone formation in Chinese patients with hip fracture. Calcified tissue international. 1995;56(5):347-9.

30. Christiansen C, Riis BJ, Rodbro P. Prediction of rapid bone loss in postmenopausal women. The Lancet. 1987;329(8542):1105-8.

31. Garnero P, Hausherr E, Chapuy MC, Marcelli C, Grandjean H, Muller C, Cormier C, Breart G, Meunier PJ, Delmas PD. Markers of bone resorption predict hip fracture in elderly women: the EPIDOS Prospective Study. Journal of Bone and Mineral Research. 1996 Oct;11(10):1531-8. 